\title{
Labyrinthe
}

32 | 2009 (1)

Le petit théâtre intellectuel

\section{Le Comique}

\section{Renaud Pasquier}

\section{(2) OpenEdition}

\section{Journals}

Édition électronique

URL : http://journals.openedition.org/labyrinthe/3982

DOI : $10.4000 /$ labyrinthe.3982

ISSN : 1950-6031

Éditeur

Hermann

Édition imprimée

Date de publication : 19 juin 2009

Pagination : 23-27

ISBN : 978-2-7056-6885-3

\section{Référence électronique}

Renaud Pasquier, «Le Comique », Labyrinthe [En ligne], 32 | 2009 (1), mis en ligne le 01 février 2011, consulté le 19 avril 2019. URL : http://journals.openedition.org/labyrinthe/3982 ; DOI : 10.4000/ labyrinthe.3982 


\section{ACTE I : CARACTÈRES}

J'ai pris un trait d'un côté et un trait d'un autre; et de ces divers traits qui pouvaient convenir à une même personne, j'en ai fait des peintures vraisemblables, cherchant moins à réjouir les lecteurs par le caractère, ou comme le disent les mécontents, par la satire de quelqu'un, qu'à leur proposer des défauts à éviter et des modèles à suivre.

Jean de La Bruyère, Discours de réception

à l'Académie française, 1693.

\section{Le Comique}

Le spectacle s'achève après deux rappels sous les applaudissements d'un public comblé. Le Comique, épuisé, savoure son triomphe. Ce soir encore, il s'est dépensé, convulsé sur la scène, riant, pleurant, vociférant. Ce soir encore, ses sketches ont fait mouche. Il a décoché ses meilleurs répliques, celles qui on fait sa gloire et qu'on répète en pouffant de la cour d'école au salon bourgeois, du dîner chic à la réunion de travail. Il en a testé de nouvelles, a beaucoup improvisé, joué avec les mots. Il sait l'art d'exercer sur la langue d'inédites torsions - « je dois tout à Devos, c'est un modèle, un maître à penser »-, la mener où elle n'irait pas d'elle-même, forgeant dans la blague des tournures inouïes, expressions devenues aussitôt populaires - comme lui - qu'on cite comme formules magiques ou concepts très exacts. On les étudie, même.

Il provoque la discussion, enflamme les débats. On s'arrache ses CD, ses DVD, ses livres. Les médias l'encensent, ils en appellent à Rabelais, à Molière: "les spectacles du Comique sont un miroir grossissant, ils en disent plus sur notre société contemporaine que ne sauraient le faire philosophes, écrivains, sociologues, etc. » Éloge excessif? Pas forcément. Le Comique jette une lumière crue sur les ressorts obscurs de la vie sociale, il figure le monde sous un jour nouveau: les spectateurs, sous le charme, attendent de lui, comme d'un Gourou, qu'il leur dise ce qu'ils ressentent et ce qu'ils doivent penser (pourtant il ne les épargne pas, provocateur, grossier, volontiers " scato »). Même ses proches, ses fidèles, qui le savent par cœur, se laissent surprendre par ses tours, par 
son dispositif vocal aux inépuisables variations, modulations, et accents d'emprunt: tous les possibles de la langue sont dans sa bouche - mais il excelle aussi dans les rôles muets, ou peu chargés de parole. Son corps est caoutchouc, ses traits polymorphes; un geste, un tic, suffisent à créer un personnage. Le répertoire est infini, mais non sans favoris : « le trader trotskiste ", « l'émeutière de banlieue », " l'intellectuel bègue », « le footballeur gay », et bien sûr le grand succès du moment, « la Présidente glamour ».

Les Puissants, justement, lui offrent son matériau de prédilection. Longtemps ceux-ci ne lui ont pas prêté attention, l'ont méprisé même - ne fait rire que le monstre, le grotesque, l'inférieur. Bien sûr la parole du Bouffon était sans chaînes, joyeuse exception à des règles de fer; l'ombre du Souverain, son double grimaçant qui le singe effrontément - en frôlant toujours une fatale limite. Libre, oui, mais à la mesure de ce qu'on le jugeait dérisoire. Bien des Comiques sont encore des Bouffons, pour preuve la grande tradition française des comiques de droite - la Droite entendue comme détentrice «naturelle» du pouvoir - et plus singulièrement, des imitateurs de droite: imiter, comme pour désigner l'indistinction des places, le brouillage de la frontière. Car les temps ont changé. Le Puissant se soucie du Comique, fût-il Bouffon; " il l'adore », fait-il savoir, c'est-à-dire qu'il le craint, et sollicite souvent son appui quand il ne cherche pas à le neutraliser. Quant au Bouffon, entre deux pieds de nez (on ne l'en écoute que plus religieusement), il devient grave, car pour les personnes vouées par état au comique, les choses sérieuses ont de fatales attractions : il évoque pudiquement ses douleurs cachées, ses émois face au monde comme il va, témoigne de sa croyance en des valeurs solides et ancestrales, qui l'ont fait ce qu'il est, et qu'il entend transmettre. Symétriquement, c'est alors le Puissant qui imite le Comique - quand jadis il prenait la vêture du prêtre, ou du général. Il se veut marrant, paillard ou blagueur; et ironique, surtout, c'est-à-dire supérieur. Le « côté des rieurs », c'est celui des dominants. Le rire naît de la supériorité, ou mieux, il l'invente et l'accroît, la donnant en spectacle. Le ridicule blesse, quand il ne tue pas. Susciter le rire est un effrayant pouvoir, bien peu démocratique.

Le Comique l'a bien compris. Il voit alors plus loin, au-delà du Bouffon, de l'Humoriste ou du Chansonnier (ces chroniqueurs mondains, taquins mais bien gentils) et retourne son don satanique contre le Puissant, qu'il 


\section{ACTE I: CARACTÈRES}

effraie alors: le Comique se fait critique, il veut déranger, il y parvient. Pas assez à son goût; il envie ainsi la place considérable acquise dans le débat public par ses tonitruants semblables italiens ou états-uniens: en France, si l'on n'est marionnette, on est astreint à la bonne tenue ou à la blague inoffensive. Il songe aux exceptions, il connaît par cœur la geste de Saint Coluche - "mon modèle, mon maître à penser » - la panique qu'il sema chez les Puissants, les escouades de penseurs qui le soutinrent. Mais Coluche, justement, fut neutralisé dès que sa trajectoire devint préoccupante, avant de se voir figé post-mortem dans le consensus larmoyant. Le Comique se rêve alors Lenny Bruce, acide et scandaleux, ou plutôt Pierre Desproges - "mon maître à penser, mon modèle » tout de même plus fréquentable. Le Comique devient méchant, il appuie « là où ça fait mal » et dit « tout haut ce que tout le monde pense tout bas » (qui le critique méprise le peuple, dont il se délire Porte-parole); bref, il est politiquement incorrect: au risque de tomber dans la bêtise sinistre, de s'enfoncer dans une grasse beaufitude. C'est le naufrage, la fin du Grand Clown. Certains ont ainsi sombré, pas forcément les moins doués au départ.

Quoi qu'il en soit, à l'âge du Spectacle, le nôtre, le Comique règne - couronné par la toute-puissante industrie du divertissement. Nous, les suppôts du Sérieux, les chercheurs, les doctes, devons courber l'échine. Il nous suffisait naguère d'être spirituels : à présent nous peaufinons nos « blagues de colloque », nous élaborons fébrilement nos gags, nous nous éreintons à ne point ennuyer, à paraître malicieux, farfelus, excentriques, amusants comme tout. Dans les médias les places sont chères, et le temps plus encore. Il faut faire vite, et efficace. Nous devenons histrions: le sketch est le meilleur moyen, la seule prise de parole possible. Avoir sa formule, sa grimace, son personnage. Au risque de perdre tout crédit, de s'enfoncer dans le rôle du Pitre. "Allons allons, me dit-on, il est, chez les sachants, plus de lugubres que de rigolos ». Certes, la grisaille chiffrée de l'Expert et les funèbres aphorismes des Pythies semblent bien loin des facéties du Comique. Et pourtant, ce « lugubre », gage de sérieux et compétence, n'est-il pas encore un masque, encore une façon de se soumettre au Comique, à ses pompes et à ses œuvres? Manière de devenir non pas son autre, mais son faire-valoir, son ombre, une sousespèce en quelque sorte, en deux mots: le Clown blanc (qui est aussi parfois Bouffon). 
Tenons alors que le grand penseur, comme le grand artiste, est celui qui n'a pas peur du ridicule, qui l'affronte crânement, au risque d'y tomber. L'œuvre forte n'a-t-elle pas toujours quelque chose d'un peu grotesque, du moins au premier abord? Notre morne époque a besoin d'Augustes, prenant acte de la situation, la creusant et l'exagérant à plaisir, mal élevés, mauvais citoyens, irrécupérables, qui vocifèrent leur savoir et leurs concepts comme des obscénités, qui fassent se lever vers eux des regards incrédules et horrifiés, satyres corrupteurs, bidonnants et bedonnants, dont le rire énorme fasse trembler les Olympes.

R. P.

\section{Bibliographie, références, lectures}

I. Baudelaire s'est souvent attardé sur l'art du comique, pour le peindre et l'analyser (insistant notamment sur le rôle du sentiment de supériorité dans le rire) en particulier:

- «De l'essence du rire et généralement du comique dans les arts plastiques », dans Critique d'art, Paris, Folio essais, 1992, p. 185-203.

- «Une mort héroïque », dans Le Spleen de Paris, in Cuvres complètes, éd. par Claude Pichois, vol. I, Gallimard, «Bibliothèque de la Pléiade », 1975-1976, p. 321.

Quelques segments de phrases sont empruntés à ces deux textes (sur le rire et la supériorité; sur la performance même du Comique).

II. Études sur le comique: Gérard Genette, « Morts de rire », dans Figures V, Paris, Le Seuil, « Poétique », 2002 (pp. 134-225), quant à l'aspect langagier; Olivier Mongin, Éclats de rire, variations sur le corps comique, Paris, Le Seuil, « La couleur des idées », 2002, quant à la dimension corporelle. Et plus encore, du même Olivier Mongin, De quoi rions-nous? La société et ses comiques, Plon, 2006.

III. La place considérable prise par le Comique dans les sociétés contemporaines est illustrée notamment par le film King of Comedy (La Valse des pantins), de Martin Scorsese, avec Robert De Niro et Jerry Lewis.

IV. Parmi les « escouades de penseurs » entourant Coluche en 1981, on songe notamment à Jean-François Lyotard et Pierre Bourdieu.

V. Jean-Marie Bigard, Lionel Duroy, Rire pour ne pas mourir, Oh! Éditions, 2007.

VI. De Lenny Bruce, véritable légende américaine, artiste controversé et craint dans les années soixante, on lira le portrait fragmenté brossé par Don DeLillo 


\section{ACTE I: CARACTÈRES}

dans Outremonde (Actes Sud, trad. M. Véron, 2003), où Bruce commente à sa manière la crise des missiles et l'affaire de la Baie des Cochons, en 1962. Quelques segments de phrase sont empruntés aux pp. 602-605.

VII. The Comedian est un personnage central de Watchmen (cf. Labyrinthe $\mathrm{n}^{\circ}$ 25), la célèbre bande dessinée d'Alan Moore et Dave Gibbons (la traduction par « Comique » aurait été préférable au «Comédien » de la version française; en italien, le personnage est bien (l Comico): il évoque à la fois, entre autres, le très patriotique Captain America et le maléfique Joker (autre figure de comique inquiétant); c'est un mercenaire nihiliste qui n'a d'autre loi que celle du plus fort.

VIII. Les « semblables italiens ou états-uniens » font notamment allusion aux figures de Stephen Colbert, Jon Stewart ou Tina Fey (pour les États-Unis) et à celles de Beppe Grillo et Sabina Guzzanti (pour l'Italie). Voir, pour ces deux derniers, la section « Portraits » de ce même numéro.

IX. Victor Hugo, « Le Satyre », dans La Légende des siècles (Première Série, chant VIII: "Seizième siècle, Renaissance, Paganisme »). Le Satyre est bien ce personnage répugnant et grotesque, qui dégoûte les Dieux tout en les faisant se tordre (sic). Son chant pourtant les jette dans l'effroi, et proclame leur déchéance.

$\mathrm{X}$. Tous les dialogues de Platon mettant en scène Socrate, comique athénien (pour une version plus critique, mais non moins comique, voir Les Nuées, d'Aristophane).

XI. Sur l'histrionisme universitaire, on se reportera aux romans de David Lodge (Changement de décor, Un tout petit monde, etc.).

XI. L'ensemble est nourri par les sketches (volontaires ou non) de Raymond Devos, Jamel Debbouze, Coluche, Pierre Desproges, Guy Bedos, Patrick Sébastien, Thierry Le Luron, Laurent Gerra, Dieudonné, Les Nuls, Les Guignols, Jean-Marie Bigard, Les Inconnus, Stéphane Guillon, etc. 